\title{
Colonialidade Interna, Cultura e Mestiçagem: repensando o conceito de colonialismo interno na antropologia contemporânea
}

\author{
Letícia Cesarino \\ Universidade Federal de Santa Catarina, Florianópolis, Santa catarina, Brasil \\ E-mail: leticia.cesarino@ufsc.br
}




\section{Resumo}

Este artigo propõe recuperar a noção clássica de colonialismo interno a partir de questões suscitadas pela literatura pós-colonial, propondo falar de colonialidade interna. Recorre-se a essa perspectiva para lançar nova luz sobre o tema da ideologia da identidade nacional mestiça no Brasil. Conclui-se trazendo linhas contemporâneas da antropologia brasileira que poderiam enriquecer a perspectiva pós-colonial, ao abordar não apenas o conteúdo da ideologia da mestiçagem, mas sua gramática subjacente, baseada na noção de cultura.

Palavras-chave: Antropologia. PósColonial. Colonialismo Interno. Colonialidade. Mestiçagem.

\section{Abstract}

This article reclaims the classic notion of internal colonialism from the point of view of questions raised by the postcolonial literature, proposing to speak of internal coloniality instead. It shows how this perspective may shed new light on the issue of Brazil's miscegenated national identity. It concludes by deploying contemporary works in Brazilian anthropology that could enrich it by approaching not just the ideology of mestiçagem, but its underlying culturalist grammar.

Keywords: Anthropology. Postcolonial. Internal Colonialism. Coloniality. Miscegenation. 


\section{Introdução ${ }^{1}$}

Desde os anos 1960 e 1970, quando a noção de colonialismo interno alcançou proeminência nas ciências sociais latino-americanas (Stavenhagen, 1963; González Casanova, 1963; Cardoso de Oliveira, 1966), não se ouve falar muito no conceito na antropologia brasileira. Este artigo propõe restituir ao vocabulário conceitual da disciplina essa noção, em larga medida relegada a seu passado. Embora o termo continue sendo utilizado de modo pontual por antropólogos contemporâneos - por exemplo, Viveiros de Castro (1999); Carvalho (2002); Velho $(2008 ; 2010)$, ele parece carecer de uma formulação mais ampla, sistemática, reflexiva e em sintonia mais fina com campos de estudo e debates (meta)teóricos recentes. Assim, proporei aqui resgatar e retrabalhar a noção de colonialismo interno a partir de temas e questões salientes na literatura contemporânea, como foco na interface entre a antropologia e os estudos pós-coloniais.

A primeira seção recupera parte da trajetória e do sentido original do conceito de colonialismo interno como uma perspectiva historiográficoteórica alternativa ao modelo, mais difundido historicamente nas ciências sociais, de construção da nação. A seção seguinte discute uma reformulação possível da noção de colonialismo interno a partir de certas propostas avançadas no campo dos estudos pós-coloniais - propondo assim falar em colonialidade interna. A terceira seção explora a possibilidade, já implicada em algumas análises, de que a mestiçagem como ideologia da identidade nacional hegemônica no Brasil e em outras partes da América Latina possa ser (re)pensada nos termos de uma colonialidade interna. Por fim, a última seção retorna à antropologia, explorando como algumas linhas da crítica contemporânea 
à noção de mestiçagem e à sua gramática subjacente, baseada na noção de cultura, poderiam enriquecer a perspectiva sobre a colonialidade interna a partir de insights próprios da disciplina antropológica.

\section{Da Construção da Nação ao Colonialismo Interno}

Nas ciências sociais brasileiras, o termo construção da nação também conhecido por meio do anglicismo nation-building - tem sido a escolha mais comum para designar os processos históricos por meio dos quais as nações pós-coloniais foram formadas, juntamente com o seu outro lado da moeda, os processos de formação do estado (ou state-formation). Nation-building_foi a noção utilizada, por exemplo, por George Stocking Jr. (1982) no conhecido número da revista Ethnos sobre antropologias centrais e periféricas. Nesse debate - precursor de discussões que viriam a ser desenvolvidas sob a alcunha de "antropologia no plural" (Peirano, 1991) ou, mais recentemente, "antropologias mundiais" (Ribeiro; Escobar, 2006) -, antropologias "periféricas" como a brasileira se diferenciariam de antropologias "centrais" como a britânica, americana e francesa pela sua ligação histórica com processos de construção da nação, em contraste com o ímpeto imperialista destas últimas.

Não obstante a justeza do contraste entre os estados-nação póscoloniais e os grandes impérios ocidentais que os colonizaram, ele parte de um divisor que superestima a ruptura pós-colonial. Como vários dos autores que abordo aqui, parto da constatação de que muitos dos processos históricos que marcaram a construção e perpetuação dos impérios coloniais têm análogos internos nos estados-nação nascidos a partir de ex-colônias. É nesse sentido que a ideia de colonialismo interno vem lançar luz sobre processos e relações que são normalmente obscurecidos por noções mais comuns como a de construção da nação, e o contraste implícito que ele traz com relação à construção de impérios. Nesta seção, apontarei alguns elementos interessantes desse "giro de perspectiva" operado pela alternativa analítica do colonialismo interno.

Em primeiro lugar, é inevitável que a ideia de construção da nação tenha uma ressonância forte com o ponto de vista historiográfico dos "vencedores", ou das elites econômicas e políticas que capitanearam a 
formação dos estados-nação pós-coloniais. Esse processo de construção de hegemonias nacionais na esteira das independências, na América Latina e alhures, tem sido descrito na literatura através de noções já bem consolidadas como a "invenção da tradição" de Hobsbawm e Ranger (1984) e as "comunidades imaginadas" de Benedict Anderson (2008). Entre os avanços produzidos por essas análises estão as propostas de que estado e nação, embora intimamente interligados, foram historicamente constituídos em relativo descompasso (geralmente, a última vindo a reboque do primeiro); que não há nada imemorial, ou essencial, nas identidades nacionais; e que estes processos históricos têm envolvido relações de poder de longa duração, a partir das quais certos grupos lograram impor sua própria ideologia e interesses como horizonte hegemônico para o restante da nação.

A Formação das Almas, o clássico de José Murilo de Carvalho (1990) sobre a invenção (no sentido hobsbawniano) de um novo imaginário nacional para a nascente República brasileira é, a meu ver, exemplar deste tipo de abordagem para a construção da nação no caso do Brasil. O livro trata de como um momento histórico de ruptura institucional com o regime anterior (o Império) exigiu a reformulação relativamente abrupta de símbolos nacionais centrais como a bandeira, $\mathrm{o}$ hino, heróis e heroínas. Carvalho mostra, de modo magistral, como, para que se reverberasse de modo eficaz no imaginário do "povo" brasileiro, muitas dessas tentativas de invenção de tradições republicanas tiveram que se assentar em símbolos anteriores (como o pano de fundo e a melodia da bandeira e do hino imperiais), ignorar personagens reais (como os próprios proclamadores), e reinventar personagens antigos (como o Tiradentes reconfigurado à imagem do Cristo).

Abordagens deste tipo são vitais para desconstruir o caráter dado e imemorial do estado-nação e de suas hegemonias subjacentes, mostrando que se fundamentam em processos históricos em larga medida contingentes e movidos por disputas e relações de poder. A própria antropologia tem se inspirado neste movimento analítico para desconstruir certos pressupostos que têm sustentado as pretensões de exclusivismo do ocidente europeu. É o caso, por exemplo, da conhecida digressão de Sahlins (2016) sobre um dos mais amplos e 
bem-sucedidos processos de invenção da tradição jamais levados a cabo: o Renascimento, que recuperou a Antiguidade clássica como raiz da modernidade europeia, ao mesmo tempo em que invisibilizou todo o período histórico medieval como a era das trevas, da barbárie e do obscurantismo, em contraposição à era das luzes que se abria.

Entretanto, este tipo de abordagem acaba dando pouca atenção ao outro lado da equação da nação: os "perdedores" da história, como eles assim o tornaram, e quais os efeitos duradouros da condição de subalternidade. Ainda nos anos 1960, intelectuais latino-americanos vinham gestando uma perspectiva alternativa à da construção nacional, encapsulada no conceito de colonialismo interno. Ao que tudo indica, o termo foi primeiro utilizado com referência ao caso paradigmático da segregação racial na África do Sul (Marquard, 1957), embora se tenha argumentado que as preocupações que ele indica possam ser encontradas antes disso em intelectuais militantes como Lênin, Antonio Gramsci, José Carlos Mariátegui e Frantz Fanon (Gonzáles Casanova, 2007). O conceito foi se popularizando em estudos de caso pelo mundo durante a segunda metade do século $\mathrm{XX}$, para tratar, por exemplo, de minorias étnicas na Europa, do divisor norte-sul nos Estados Unidos, ou da situação dos árabes em Israel (Hechter, 1975; Williams, 1977; Hind, 1984). Todavia, seu pedigree acadêmico tem sido comumente associado a dois sociólogos mexicanos, Pablo González Casanova (1963) e Rodolfo Stavenhagen (1963), que se inspiraram, por sua vez, em sugestões feitas na época pelo sociólogo estadunidense C. Wright Mills.

No caso desses autores, o foco se volta para os grupos indígenas e campesinos de países como México, Bolívia e Guatemala, numa chave analítica mais próxima à do marxismo e da economia política, e em diálogo com a teoria da dependência, também em voga na época. Não obstante as diferentes ênfases e variações que se seguiram, o pano de fundo comum do conceito original de colonialismo interno é que, para as minorias econômicas, étnicas, políticas dentro dos estados-nação latino-americanos, o fim do colonialismo formal não significou o fim das relações coloniais. Isso porque as elites nacionais criollas, ao lograrem sua independência formal com relação à metrópole, passaram a dar continuidade ao processo colonizador domesticamente, dentro da chave 
da construção dos novos estados-nação. Stavenhagen originalmente avançou seu argumento contra perspectivas do tipo "sociedade dual" (ou seja, que supõem um divisor interno aos estados-nação entre uma parte moderna e modernizante e outra, tradicional ou atrasada), perfazendo internamente um movimento crítico análogo ao que a teoria da dependência fez internacionalmente. Ecoando as análises de Gramsci sobre as relações entre o Mezzogiorno e o norte da Itália, ele sugeriu que o subdesenvolvimento de certas populações e regiões se deve não ao seu isolamento como sociedades tradicionais, incapazes ou paradas no tempo, mas à sua participação ativa, porém desigual e periférica, em sistemas econômicos que encontram seu centro em regiões e grupos sociais domesticamente hegemônicos. As relações coloniais dentro do sistema doméstico participam, por sua vez, de processos geopolíticos e econômicos mais amplos na escala do sistema mundial, o que faz com que relações de periferalização observados na escala internacional encontrem análogos internos aos estados-nação periféricos.

Em um esforço de reelaboração posterior do conceito, González Casanova (2007) apontou como traço característico do colonialismo interno a junção entre desigualdade econômica e desigualdade étnicoracial no interior de estados-nação pós-coloniais como os latinoamericanos, onde as classes dominantes são, ou se pensam como, racialmente brancas e etnicamente descendentes dos colonizadores europeus (o que pode implicar em um divisor linguístico, ou não). Ele também notou como esse duplo divisor doméstico (étnico-racial e de classe) também tende a seguir linhas geográficas, ao longo das quais o poder político e econômico passa a se concentrar em certas regiões do país e/ou ao longo do eixo rural-urbano. Como outros, Gonzáles Casanova tem acrescentado aos eixos político-econômico, geográfico e étnico-racial, típicos do conceito original de colonialismo interno, cruzamentos com outras linhas por meio das quais tem corrido a política contemporânea, como movimentos pela igualdade de gênero, orientação sexual, ecologia, antiglobalização e precariedade neoliberal - mantendo contudo a centralidade dos movimentos indígenas como frente de resistência à hegemonia global do capital. 
$\mathrm{Na}$ antropologia brasileira, a ideia de colonialismo interno teve certa circulação nos anos de 1960 e 1970, a princípio de modo muito concentrado no âmbito da etnologia indígena. Grandes nomes do período de consolidação institucional da antropologia no país o utilizaram, notadamente Roberto Cardoso de Oliveira (1966), que mantinha um diálogo direto com seus colegas latino-americanos. Este último defendeu a relevância do conceito para pensar as relações interétnicas entre os grupos indígenas e o estado-nação brasileiro, articulando-o com correlatos como a "situação colonial" avançada por Georges Balandier (2014) a partir do contexto africano nos anos 1950. A ideia geral do colonialismo interno também permeia outras noções importantes do período, como as de fricção interétnica (Cardoso de Oliveira, 1963) e frentes de expansão (Velho, 1972). Não surpreende, portanto, que no Brasil o conceito tenha sido desde então tipicamente associado a estudos de contato, relações interétnicas, indigenismo e campesinato (Montero; Arruti; Pompa, 2012).

Mais recentemente, o termo tem aparecido em falas e escritos de antropólogos que partem de outras perspectivas e/ou trabalham outras temáticas. Eduardo Viveiros de Castro (1999, p. 173) o evocou para criticar a "brasileirização dos índios" implicada em argumentos sobre o caráter anticolonialista de antropologias periféricas como a brasileira. Otávio Velho (2008, p. 7, grifo original) o recuperou, num sentido similar, para matizar a oposição entre antropologias de construção de impérios e antropologias de construção de nações, sem, contudo, apagar o contraste entre elas - por exemplo, a ênfase especial, no caso destas últimas, no “[...] problema da unidade, pois sendo o outro interno impunha-se uma delicada operação simultânea de reconhecimento e circunscrição, num sutil - mas delicado - equilíbrio, reconhecedor, por assim dizer, da natureza antinômica do real". Essas referências são, todavia, esparsas e pontuais. Creio que os mecanismos dessa operação simultânea, e um tanto paradoxal, de reconhecimento e circunscrição, diversidade e unidade, autonomia e controle, através da qual tem se desdobrado a relação entre o estado-nação brasileiro e os grupos colonizados internamente ainda podem ser melhor explorados. 
Esse esforço implicaria pensar reflexivamente sobre a participação da própria antropologia nos processos de colonialismo interno no Brasil - como já foi feito em outras partes do mundo para o colonialismo europeu e para o imperialismo e colonialismo interno estadunidenses (Fabian, 2013; Clifford; Marcus, 2017; Asad, neste volume). Roberto Cardoso de Oliveira (2006) havia levantado essa questão da reflexividade antropológica em contextos de colonialismo interno, mas a resolveu dentro dos termos do indigenismo e da atuação de um antropólogo "cidadão". A meu ver, um dos modos de aprofundar essa reflexão de modo mais sensível às complexidades e dilemas do contexto contemporâneo do "multiculturalismo à brasileira" (e dos recentes ataques a ela) seria trazendo elementos da chamada crítica pós-colonial para pensar o processo de colonialismo interno. A seção seguinte busca ensaiar alguns apontamentos neste sentido.

\section{Do Colonialismo Interno à Colonialidade Interna}

Não obstante o avanço crítico que o conceito de colonialismo interno perfaz com relação a abordagens do tipo nation-building ou sociedades duais, como qualquer outro, ele encontra limitações relativas ao campo de debates e à época no qual surgiu. Neste caso, a ideia original do colonialismo interno diz respeito fundamentalmente a temas e questões do marxismo, economia política, sistemas mundiais, e outras perspectivas dominantes nas ciências sociais latino-americanas nas décadas de 1960 e 1970 ( Stavenhagen, 1963; González Casanova, 1963; Cardoso de Oliveira, 1966; Velho, 1972). Desde então, a antropologia e as demais ciências sociais têm caminhado no sentido de incorporar outros aportes teóricos que permitem lançar uma luz mais refinada sobre questões relativas à "superestrutura". Um autor importante nesse sentido tem sido Antonio Gramsci e sua dupla analítica da hegemoniasubalternidade (Gramsci, 1999), que formou a base de boa parte do campo acadêmico dos estudos pós-coloniais. ${ }^{2}$ Entre conexões mais conhecidas no Brasil estão os subaltern studies indianos e o artigo pioneiro de Stuart Hall (2003) sobre a relevância de Gramsci para o estudo da raça e etnicidade. Além destes, o grupo de acadêmicos que eventualmente 
se desdobrou no programa da modernidade-colonialidade - mais conhecido através da noção de giro decolonial - começou como um tipo de subaltern_studies latino-americano, inspirado na proposta pioneira dos colegas indianos (Escobar, 2007; Ballestrin, 2013).

Muito já foi dito e debatido, nos últimos 20 ou 30 anos, sobre se seria possível ou desejável voltar lentes pós-coloniais para a América Latina; que deslocamentos e inovações emergiriam desse movimento; quais seriam as especificidades do pós-colonial no campo lusófono, em geral, e no Brasil, em particular; ou se a própria importação dessas lentes, desenvolvidas a partir de contextos de colonização diferentes e bem mais recentes que os da América Latina, não constituiria ela mesma um tipo de colonialismo acadêmico (Mignolo, 1993, 2005a; Aschcroft, 1998; Santos, 2003; Moraña et al., 2008; Moraña; Jáuregui, 2008). Há sem dúvida variações importantes neste campo de debates, mas parece haver consenso em torno da tese mais geral de que a conquista e colonização das Américas marcam a origem da modernidade europeia, compondo, portanto, seu "lado obscuro" e ainda não plenamente reconhecido (Mignolo, 2005a, 2011; Escobar 2007). Segundo essa perspectiva, esse lado oculto, porém íntimo e indissociável, da modernidade foi durante muito tempo invisibilizado pela historiografia do mainstream, que tende a tomar processos modernos como o iluminismo, revolução científica, industrial, capitalista, etc, como endógenos à história europeia (Moraña et al., 2008; Moraña; Jáuregui, 2008).

Esse esforço de "provincializar" a história da modernidade europeia (Chakrabarty, 2000) a partir do ponto de vista da colonização das Américas tem se desdobrado em direções variadas de pesquisa: colonização e subalternização de outras formas de vida como processo necessário e constitutivo da emergência modernidade ocidental (Escobar, 2007); recuperação dos iluminismos ibéricos e de suas influências na ciência e na filosofia modernas (Cañizares-Esguerra, 2006); emergência da América Latina como região constituinte, porém marginal e subalterna, do ocidente (Mignolo, 2005b; 2011); consideração do caráter de "colonizador subalterno" dos impérios português e espanhol, e suas consequências de longa duração para suas ex-colônias, na América Latina, África e alhures (Santos, 2003); recuperação de autores e linhas de pensamento nascidos da experiência 
latino-americana, como o marxismo de Mariátegui ou a teologia da libertação (Moraña et al., 2008); repensar processos de construção da nação sob uma perspectiva de sistemas mundiais e modernidades subalternas (Coronil, 1997); e, de modo mais amplo, atenção aos efeitos duradouros do colonialismo para além do período colonial propriamente dito, e extensão da influência metropolitana para além do colonizador original, abarcando também outras ondas de hegemonia global, em especial o imperialismo estadunidense e o capitalismo industrial e financeiro (Escobar, 2007).

Como intuiu Otávio Velho (2010), este último ponto aponta para um conceito abraçado por este grupo que parece ser particularmente interessante para repensar o colonialismo interno: a colonialidade do poder, do peruano Anibal Quijano (1992; 2005). Quijano articula suas reflexões sobre a estrutura duradoura de poder legada pela colonização europeia aos países da América Latina em torno da ideia de raça, ou da naturalização das diferenças - cujas raízes podem ser traçadas até o encontro colonial inaugural em 1492. Na formulação original desse autor, esse sistema classificatório hierárquico centrado na categoria de raça constituiu a base para o controle do trabalho pago e não-pago (em especial, dos indígenas) necessário à emergência e expansão do capitalismo industrial. O conceito de colonialidade foi progressivamente expandido por Quijano e outros para abarcar uma cadeia interconectada de hierarquias globais que extrapolam a dominação militar e econômica para incluir eixos epistêmicos, linguísticos, de gênero, sexualidade, espiritualidade, relação com a natureza, subjetividades, formando o que estes autores chamam de "sistema mundial colonial moderno" (Escobar, 2007, p. 185; Quijano; Wallerstein, 1992) ou "matriz de poder colonial" (Mignolo, 2011, p. 156; Moraña et al., 2008; Moraña e Jáuregui, 2008; Lugones, 2014). O conceito de colonialidade se coloca como uma alternativa interessante à ideia do pós-colonial, por ser menos vaga e ambivalente, derivar de um ponto de vista latinoamericano, e evidenciar melhor os elementos relacionais, multiescalares e historicamente situados dos processos em questão. ${ }^{3}$

Dentro do quadro latino-americano mais geral, o caso brasileiro tem, ainda, especificidades próprias. Algumas das reflexões a meu ver 
mais perceptivas no sentido de pensar a história do país numa chave pós-colonial vieram de um português, Boaventura de Sousa Santos (Cesarino, 2012). Em um artigo paradigmático originalmente publicado no ano de 2001, Santos (2003, p. 29) levantou a necessidade de se pensar não no pós-colonial em termos gerais, mas em pós-colonialismos situados baseados em "[...] cuidadosas análises históricas e comparadas dos colonialismos e do que se lhes seguiu". No caso de Portugal, ele discutiu os efeitos, sobre suas as ex-colônias, do fato de terem tido um "colonizador subalterno" nos termos da hegemonia continental que gradualmente se deslocou, a partir do século XVII, para os grandes impérios da Europa ocidental, em especial Inglaterra e França. Mesmo nos termos do colonialismo ibérico, Portugal teve uma trajetória particular, como a submissão temporária à Espanha entre os séculos XVI e XVII, a transferência da sede do império para uma de suas colônias (o Brasil) no início do século XIX, e o consequente caráter conservador da independência deste último - levando à manutenção da unidade territorial da ex-colônia, em contraste com a intensa fragmentação política do ex-império espanhol. Santos (2003, p. 29) especula que esse "déficit de colonialismo" por parte de Portugal possa ter levado, após a independência em 1822, a um tipo de colonialismo interno especialmente forte no caso brasileiro. Como consequência dessa "dupla ambivalência" do seu colonizador subalterno, a colonialidade no Brasil teria vindo a se caracterizar por algumas disposições paradoxais, como uma complexa sobreposição de camadas de colonialidade (Inglaterra, Estados Unidos...), uma relação "amigável" com o ex-colonizador original, e, domesticamente, uma peculiar "fratura ... entre os que se sentem vergados pelo excesso de passado e os que se sentem vergados pelo excesso de futuro" (Santos, 2003, p. 28).

A própria antropologia, como as outras ciências sociais brasileiras, não poderia deixar de estar implicada nesses processos. Com efeito, retrospectivas históricas da disciplina no Brasil têm apontado uma relação importante entre esta e o colonialismo interno, por meio da sua associação orgânica com o problema da construção da nação (Peirano, 1999). O conhecido comentário de Lília Schwarcz (1999) de que a antropologia brasileira se constituiu com base em objetos específicos, mais do que em temas ou teorias, é bem evocativo desta 
relação: antes de serem objetos do olhar teórico da disciplina, indígenas e afro-brasileiros foram os principais objetos do colonialismo interno do estado brasileiro. E embora a antropologia faça parte de um sistema relativamente autônomo com relação ao estado (Cesarino, 2017a), muitas de suas categorias constitutivas são herança dessa relação colonial. Um indicativo revelador (e para alguns, incômodo) disso é o fato de, ainda hoje, as suas subáreas serem definidas pela burocracia estatal em termos de linhas demarcatórias clássicas do colonialismo interno brasileiro: Antropologia das Populações Afro-Brasileiras, Etnologia (indígena), Antropologia Urbana e Antropologia Rural restando a Teoria Antropológica como categoria residual.

Antropóloga brasileira radicada nos EUA, Teresa Caldeira (2000, p. 22) foi dos poucos a colocar a questão da produção da alteridade antropológica no Brasil explicitamente em termos de relações de poder na escala doméstica:

Os intelectuais brasileiros, inclusive antropólogos, têm estudado preferencialmente grupos sociais subalternos: o pobre, o negro, o índio, o membro de minorias étnicas ou sexuais, e os trabalhadores organizadores de movimentos sociais.

Conclui ela que "[...] a alteridade torna-se, assim, uma questão de relações de poder, mas neste caso as relações são intrínsecas à sociedade dos antropólogos" (Caldeira, 2000, p. 22). A escassez de reflexões neste sentido, embora desalentadora por um lado, é por outro compreensível: provavelmente resulta menos de uma cegueira para conexões tão evidentes do que de um posicionamento estratégico da disciplina nos termos da sua delicada posição histórica como mediadora (e aliada política) entre essas populações e o estado. Mas como sugeri em outra ocasião (Cesarino, 2017a), é preciso também atentar para a complexidade das conexões entre antropologia e colonialidade interna: se os antropólogos têm sido tradicionalmente membros das "elites" nacionais, como afirma Caldeira, essas elites não são nem monolíticas, nem destituídas de hierarquias e conflitos internos.

Não obstante certa timidez reflexiva, na antropologia brasileira das duas últimas décadas têm emergido alguns esforços mais ou 
menos isolados no sentido de pensar o colonialismo interno brasileiro através de insights derivados do campo contemporâneo dos estudos pós-coloniais. Em um livro originalmente publicado em inglês, Alcida Ramos (1998) propôs um exercício pioneiro de pensar o indigenismo brasileiro através do conceito saidiano do orientalismo (Said, 2007). Ela transpôs a perspectiva de Said sobre a relação Ocidente/Oriente para pensar as visões (hegemônicas) do estado e da sociedade nacionais brasileiros sobre os grupos indígenas (subalternos) localizados em seu território. É interessante notar, em sua análise, paralelos claros com características típicas da mecânica do orientalismo saidiano, como a auto-referência (ou seja, um discurso que diz mais sobre aquele que vê do que sobre aquele que é visto), a homogeneização e reificação do objeto do discurso orientalista (o "índio hiper-real" de Ramos), e o caráter contraditório dos estereótipos a ele associados. Assim como convivem, no orientalismo clássico, a imagem do ditador bárbaro e sanguinário e do guerreiro nobre e corajoso, da odalisca exótica, sensual e sexualmente disponível para o homem branco e da mulher oprimida sob sua burca, coexistem, no orientalismo da colonialidade interna brasileira, o índio primitivo e canibal, e o índio puro e bom selvagem; o índio incapaz, infantil e preguiçoso, e o índio hábil no trato dos perigos e desafios da floresta; a herança indígena que atrasa o progresso, e as suas contribuições civilizatórias para o país. Assim como no orientalismo clássico (como no discurso foucaultiano), não importa qual o conteúdo do estereótipo em jogo - o ponto essencial é que ele diz respeito menos ao seu objeto "real" do que ao posicionamento do enunciador numa relação de poder com relação a este último.

Outros tipos de processos de colonialismo interno também já foram pensados através da inspiração pós-colonial - aqueles que correm, por exemplo, em linhas regionais. Em particular, Durval Albuquerque Jr. reconstruiu o processo histórico e literário de construção da alteridade regional que ele chamou de A Invenção do Nordeste - uma ressonância clara com outros volumes na linha da crítica pós-colonial como $A$ Invenção de África de Valentin-Yives Mudimbe (2013), A Ideia da América Latina de Walter Mignolo (2005b), e o subtítulo da edição brasileira do Orientalismo, de Said (2007). Não se trata aqui exatamente da 
invenção da tradição no sentido de Hobsbawm e Ranger (1984), mas da produção discursiva de um "outro" (interno ou externo) por meio de relações de colonialidade que também percorrem outros eixos. No caso do nordeste, como em outros, a colonialidade interna tende a seguir linhas geográficas: divisores como litoral/interior e rural/urbano foram historicamente centrais tanto às diversas "interpretações do Brasil" quanto a políticas concretas avançadas pelo estado. Cabe notar como esses divisores produzem internamente efeitos de colonialidade semelhantes a (e interconectados com) aqueles observados externamente. É o caso da alocronia (Fabian, 2013) entre sertão e litoral tão eloquentemente expressa por Euclides da Cunha, e das disjunções e paradoxos a que ela leva - "Porque não no-los separa um mar, separam-no-los três séculos". (Euclides da Cunha, 2007, p. 209). ${ }^{4}$

Alguns autores, em especial ligados à perspectiva decolonial, já abordaram a questão do colonialismo interno a partir da perspectiva da colonialidade do poder. Mignolo, por exemplo, o sugeriu ao falar sobre a dupla diferença colonial que formou as elites criollas da América Latina, em sua relação com a Europa, por um lado, e com as populações ameríndias e afrodescendentes por outro:

A diferença colonial transformou-se e reproduziu-se no período nacional, passando a ser chamada de 'colonialismo interno'. O colonialismo interno é, assim, a diferença colonial exercida pelos líderes da construção nacional. (Mignolo, 2005a, p. 43)

Outros autores falaram explicitamente em termos de uma colonialidade interna, porém sem desenvolvê-la mais a fundo como um conceito específico (Lander, 2005). Na antropologia brasileira, embora intuída por alguns (Velho, 2010), até onde pude averiguar a ideia de colonialidade interna nunca foi trabalhada. A seção seguinte busca ensaiar um exercício deste tipo, tomando como foco a ideologia de nation-building historicamente hegemônica no Brasil, assim como em boa parte da América Latina: a mestiçagem. 


\section{Colonialidade Interna e Mestiçagem}

A mestiçagem talvez tenha sido o tema mais referenciado e trabalhado no corpus literário e acadêmico das humanidades brasileiras, ao menos desde o célebre ensaio fundador de Von Martius de 1843 sobre "como se deve escrever a história do Brasil". É possível dizer algo novo sobre ele? Partindo do contexto contemporâneo de crise do paradigma hegemônico da identidade nacional centrado na mestiçagem, e da concomitante emergência de novas políticas da identidade, do reconhecimento ou da diferença, vale experimentar com formas renovadas de olhar para esta velha questão. Uma mirada pós-colonial na mestiçagem como um eixo importante da colonialidade interna brasileira implica repensar alguns de seus mecanismos e efeitos duradouros sob uma nova luz - é o que pretendo ensaiar nesta seção.

Talvez seja útil começar com mais um paralelo com os EUA. Naquele país, o revisionismo historiográfico da principal narrativa hegemônica sobre a construção da nação americana - a notória "tese da fronteira" de Fredrick Jackson Turner - convergiu com a intensificação das políticas de reconhecimento naquele país. O conhecido argumento de Turner para a singularidade histórica da democracia americana baseou-se numa imagem do Oeste como wilderness, lugar de terras disponíveis a serem progressivamente anexadas por pioneiros devotos, individualistas, e profundamente desconfiados da autoridade e da centralização estatais. Assim teria sido moldado o "caráter americano" e seu "destino manifesto" de levar liberdade e democracia para aqueles que não as tinham - primeiro adjacente e internamente ao território nacional e, posteriormente, fora dele.

O revisionismo historiográfico da tese tem privilegiado, por outro lado, a inserção da "corrida para o oeste" numa geopolítica mundial mais ampla, bem como o seu caráter colonizador e complexo com relação, em especial, às populações indígenas, grupos hispânicos e imigrantes asiáticos que foram trazidos à nação sob a égide da hegemonia branca protestante. Uma das tendências, de cunho "multiculturalista", tem sido (re)ver o processo menos como uma fronteira separando settlers (cultura) de wilderness (natureza), mas como uma "encruzilhada" onde convergiram, de múltiplas formas, diferentes histórias e povos (Massip, 
2012). Outra, de viés mais "pós-colonial", implica ver esse mesmo processo em termos de lacunas no arquivo histórico que precisam ser recuperadas, da produção de subjetividades múltiplas e divididas, das possibilidades de alianças entre diferentes grupos subalternos, e outras preocupações típicas da literatura pós-colonial (Singh; Schmidt, 2000). Acredito que seja possível revisitar a principal narrativa da construção da nação brasileira - o "mito das três raças" - ao longo de linhas de colonialidade interna similares a estas últimas.

Assim, se a ideologia da mestiçagem foi o horizonte hegemônico da identidade nacional brasileira durante boa parte do século XX, o pernambucano Gilberto Freyre foi sem dúvida - para continuar com o idioma gramsciano - seu principal intelectual orgânico. Em escritos anteriores, trabalhei como Freyre consolidou uma gramática culturalista na relação do estado brasileiro com seus grupos subalternos, cuja operação guarda paralelos importantes com a mecânica do orientalismo saidiano. O meu objetivo então era mostrar como este tipo de orientalismo interno vinha sendo historicamente projetado para fora, na escala internacional das relações entre Brasil e o continente africano (Cesarino, 2012; 2017a). Aqui, desejo apenas fazer alguns breves apontamentos no sentido de possíveis caminhos para pensar a ideologia da mestiçagem como uma engrenagem central da colonialidade interna brasileira, enfocando a sua gramática culturalista subjacente.

Um ponto de partida produtivo, neste sentido, é o Prefácio original de Freyre (2005) para a primeira edição de Casa Grande $\theta$ Senzala. Retoma-se a seguinte passagem, bem conhecida dos antropólogos:

O professor Franz Boas é a figura de mestre de que me ficou até hoje maior impressão. Conheci-o nos meus primeiros dias em Colúmbia. Creio que nenhum estudante russo, dos românticos, do século XIX, preocupou-se mais intensamente pelos destinos da Rússia do que eu pelos do Brasil na fase em que conheci Boas. Era como se tudo dependesse de mim e dos de minha geração; da nossa maneira de resolver questões seculares. E dos problemas brasileiros, nenhum que me inquietasse tanto como o da miscigenação. Vi uma vez, depois de mais de três anos maciços de ausência do Brasil, um bando de marinheiros nacionais - mulatos e cafuzos - descendo não me lembro se do São Paulo ou do Minas pela neve 
mole de Brooklyn. Deram-me a impressão de caricaturas de homens. E veio-me à lembrança a frase de um livro de viajante americano que acabara de ler sobre o Brasil: "the fearfully mongrel aspect of most of the population". A miscigenação resultava naquilo. Faltou-me quem me dissesse então, como em 1929 Roquette-Pinto aos arianistas do Congresso Brasileiro de Eugenia, que não eram simplesmente mulatos ou cafuzos os indivíduos que eu julgava representarem o Brasil, mas cafuzos e mulatos doentes.

Foi o estudo de antropologia sob a orientação do professor Boas que primeiro me revelou o negro e o mulato no seu justo valor - separados dos traços de raça os efeitos do ambiente ou da experiência cultural. Aprendi a considerar fundamental a diferença entre raça e cultura; a discriminar entre os efeitos de relações puramente genéticas e os de influências sociais, de herança cultural e de meio. Neste critério de diferenciação fundamental entre raça e cultura assenta todo o plano deste ensaio. (Freyre, 2005, p. 31)

Após ler Pele Negra, Máscaras Brancas (Fanon, 2008), as impressões de Freyre sobre os marinheiros mestiços brasileiros como "caricaturas de homens" passaram a soar como um tipo de momento fanoniano. A situação é, porém, diferente: não se trata de ver a si mesmo por meio do olhar de um outro (racista), como aconteceu tragicamente com Fanon (2008, p. 105) no trem. Trata-se, aqui, de um membro da elite branca do Brasil olhando para exemplares do povo mestiço brasileiro e vendo-os como eles seriam vistos por um outro (racista) desta feita, não uma criança francesa, mas um "viajante americano". O olhar de Freyre para os marinheiros mestiços é aquele da colonialidade interna; mas este olhar inferiorizante é, ele mesmo, profundamente moldado por uma outra relação de subalternidade, vis-à-vis um outro hegemônico. Nessa "dupla-consciência criolla" - para usar o termo de Mignolo inspirado em W. E. B. Du Bois (1999) -, a subjetividade do intelectual da elite nacional encontra-se cindida entre essas duas relações: uma na qual ele é (para manter o idioma hegeliano de Fanon) o senhor, e outra na qual ele é o escravo, e onde ambos - o mestiço brasileiro e o viajante americano - são a um tempo "outro" e "eu" para ele. Nessas lembranças, as inquietações do jovem Gilberto teriam sido 
apaziguadas caso alguém lhe tivesse convencido de que ofearfully mongrel aspect daqueles homens derivava menos da (lei de ferro) da biologia do que de um ambiente desfavorável (mas não obstante moldável) que os tornava "doentes". Alguns anos depois, Freyre identificaria esse "alguém" com ninguém menos que Franz Boas, o fundador da antropologia cultural americana.

De um ponto de vista antropológico, é interessante explorar mais a fundo o papel central desempenhado pela gramática da cultura aqui. Já foi dito que a influência atribuída por Freyre a Boas é mais retrospectiva do que representativa da sua real experiência como estudante em Columbia, e que mais decisivo para seu pensamento teria sido sua estadia no Texas, onde o brasileiro pôde vivenciar em primeira mão o ápice da segregação racial nos EUA (Pallares-Burke, 2005). Não obstante, o que interessa aqui é justamente a atribuição que é feita, e o lugar central que a analítica baseada na cultura passa a assumir desde então, deslocando a perspectiva centrada na raça biológica - um verdadeiro paradigm shift kuhniano. Para continuar com a analogia, assim como o paradigma permite aos cientistas (literalmente) verem certas coisas e não outras, ainda que o que não seja visto permaneça latente e possa eventualmente emergir como anomalia (Kuhn, 1997), também a gramática culturalista - se não inaugurada, ao menos refinada e popularizada por Freyre - passou a conformar um campo discursivo difuso nas relações raciais brasileiras, obviando o eixo racial sem, no entanto, eliminá-lo (Cesarino, 2017a).

Mas por que, justamente, a noção de cultura? Considerando o contexto de emergência das teorias racialistas e eugênicas na América Latina na época (Schwarcz, 1993), não é difícil entender a produtividade da contraposição entre nature e nurture, entre determinismo biológico e influência do meio (cultura), que subjaz (uma das vertentes do) conceito boasiano de cultura para o dilema que afligia o jovem Gilberto "e outros da minha geração" na década de $1920^{6}$. Além disso, em sua origem, o tour-de-force freyreano gerou também um efeito importante no plano da colonialidade interna: além de elevar a cultura brasileira da tolerância racial em relação aos Estados Unidos racistas e segregacionistas, internamente a narrativa de Casa Grande e Senzala também elevava a 
cultura do nordeste açucareiro de regional para nacional, num contexto em que o centro político e econômico do país já havia sido deslocado daquela região para o sudeste . $^{7}$

Todavia, ao se hegemonizar progressivamente como ossatura do caráter nacional, a cultura foi assumindo um caráter bem menos, digamos, progressista, do que no contexto original em que emergiu o culturalismo boasiano. A natureza relativamente indeterminada da noção de cultura em Boas - que, nas palavras de Visweswaran (1998, p. 72), "tornou-se tudo o que não era raça" - deu lastro a "traduções" as mais diversas quando transportada para outros contextos nacionais. Foi o caso, por exemplo, de outro ex-aluno de Boas escrevendo nos anos 1930, o etnólogo Afrikaner W. W. M. Eiselen, mencionado por Adam Kuper no início do seu livro sobre a antropologia cultural americana (Kuper, 2002). Mas enquanto no Brasil o culturalismo de Freyre buscou esvaziar o caráter problemático de uma miscigenação racial que já existia, na África do Sul Eiselen se valeu do culturalismo para impedila de acontecer, ao justificar a segregação racial como uma forma de preservar a diferença cultural.

Nota-se, portanto, como a gramática culturalista "importada" da antropologia americana foi chamada a participar, de modos variados, de processos de colonialidade interna no Brasil e alhures. Na esteira da publicação de Casa Grande e Senzala em 1933, a cultura formou a base da perspectiva hegemônica através da qual a identidade nacional passou a ser concebida, tendo sido prontamente abraçada pela Era Vargas e seu projeto populista de uma nação forte, baseada no trabalho urbano e na progressiva ocupação do interior do país. Na mesma época se consolida o ambivalente paradigma indigenista da tutela (Souza Lima, 1995), e, ao longo do século, vão se sedimentando os diversos símbolos hegemônicos da identidade nacional, todos concebidos na chave de uma cultura mestiça: samba, feijoada, carnaval, capoeira, futebol (Fry, 1977; Reis, 1993; Vianna, 1995).

Importante notar como a progressiva incorporação dos grupos subalternos no corpo político nacional através de símbolos culturais - especialmente os afrodescendentes, mas também grupos indígenas e mesmo outros de caráter regional, como os gaúchos e cangaceiros - 
seguiu-se à submissão política, econômica e, em alguns casos, militar desses mesmos grupos. Basta pensar na situação dos ex-escravos no pós-abolição relatada, entre outros, por Florestan Fernandes; nas reformas urbanas segregacionistas no Rio de Janeiro (o "berço do samba") no início do século XX; na Marcha para o Oeste e a "pacificação" e deslocamento de grupos indígenas do interior do país para áreas confinadas como o Parque do Xingu a partir dos anos 1960; na transmutação do gaúcho e do cangaceiro de "bandidos sociais" em símbolos regionais, após sua submissão militar (Ramos, 1998; Souza Lima, 1995; Vianna, 1995; Ferreras, 2003). O conhecido adágio benjaminiano de que "todo documento de cultura é também um documento de barbárie" encontra, na colonialidade interna brasileira, uma ressonância histórica particular.

Como apontei em trabalhos anteriores (Cesarino, 2012; 2017a), cabe perguntar, por fim, sobre a curiosa eficácia da gramática culturalista, que tem persistindo através das décadas não obstante mudanças significativas no seu contexto e conteúdo. Por um lado, é possível dizer que, como no orientalismo saidiano, o discurso hegemônico diz mais sobre aqueles que o enunciam do que sobre seu suposto objeto - ou, ainda, numa leitura mais forte da tese saidiana, que esse objeto não existe "como tal" fora do discurso, e portanto das relações de poder que o constituem. Nesta autorreferencialidade estaria uma chave importante para compreender sua eficácia ao longo das décadas (Cesarino, 2017a). Mas, por outro lado, como muitos antropólogos têm notado e trabalhado, a gramática da cultura tem sido enunciada e reinventada pelos próprios grupos subalternos que ela pretendeu enquadrar e objetificar durante boa parte do século XX. Refiro-me, é claro, à emergência mais recente de movimentos de resistência e reivindicação de direitos, inclusive territoriais, no contexto das possibilidades de reconhecimento aberto pela Constituição de 1988.

Chega-se, aqui, aos dilemas e tensões típicos das políticas de identidade, que já foram bastante explorados de diferentes formas na antropologia, para outros contextos sociais e geográficos como o australiano (Povinelli, 2002), africano (Comaroff; Comaroff, 2009) ou islâmico (Mahmood, 2004). Nessas análises, o diálogo com a literatura 
pós-colonial tem ajudado a compreender alguns dos paradoxos e disjunções recorrentemente observados nesses processos. Há, em cada caso, combinações emergentes e complexas entre múltiplas linhas hegemônicas e contra-hegemônicas, que vão se co-transformando através de lutas políticas concretas e historicamente específicas. No caso do Brasil, se a ideologia da mestiçagem pode ser pensada como um eixo central de colonialidade interna durante boa parte do século XX, o que significa pensar uma crítica pós-colonial no início do século XXI? Apesar de a antropologia brasileira não ter um histórico de diálogo próximo com o campo pós-colonial, alguns autores têm avançado importantes análises críticas que se aproximam de questões que foram levantadas aqui na chave da colonialidade interna. Concluo na seção seguinte discutindo algumas destas, mais especificamente, aquelas voltadas para a noção de mestiçagem e para a noção de cultura.

\section{Considerações Conclusivas: a crítica antropológica da gramática culturalista}

Na antropologia brasileira, a crítica da mestiçagem como ideologia nacional já tem sido feita há algum tempo tanto dentro quanto fora da academia, porém raramente através de um diálogo próximo com o campo pós-colonial (com reconhecidas exceções, notadamente Segato, 2010). Por outro lado, ultimamente tem-se ouvido falar muito em "descolonização", inclusive da própria teoria antropológica (Viveiros de Castro, 2015). Deve haver, portanto, muitas pontes a serem ainda lançadas entre os dois campos - como, por exemplo, as compiladas neste dossiê - mas que permitam, ao mesmo tempo, manter uma individualidade disciplinar reconhecível da antropologia. Parte desta identidade deriva do método etnográfico, e da relação peculiar que a disciplina tem estabelecido com seus sujeitos de pesquisa, boa parte dos quais seriam classificados pelo campo pós-colonial como "subalternos" (Hofbauer, neste volume). Depois de sugerir como uma noção tomada de empréstimo do campo pós-colonial - a de colonialidade - poderia ser interessante para repensar o conceito de colonialismo interno na antropologia, concluo fazendo o caminho inverso, explorando como algumas reflexões (meta)teóricas na antropologia contemporânea 
incidem criticamente sobre o tema da mestiçagem como ideologia hegemônica da identidade nacional de formas que poderiam enriquecer as perspectivas do tipo pós-colonial.

De modo mais evidente, há os esforços recentes no sentido de pensar as concepções de mistura e as relações entre os grupos subalternizados pela colonialidade interna brasileira fora da chave hegemônica da mestiçagem, do sincretismo e da fusão. Duas agendas emergentes neste sentido têm girado em torno das noções de contra- (Goldman, 2015) e antimestiçagem (Luciani, 2016). Com o termo afroindígena, Marcio Goldman experimenta com a possibilidade de tomar relações minoritárias fora dos termos estabelecidos pelo vértice hegemônico do triângulo das três raças, qual seja, o branco. Sua perspectiva se baseia fundamentalmente no exercício deleuziano de minoração, no qual se retira o polo dominante para fazer emergir agenciamentos entre indígenas e afrodescendentes que foram historicamente submergidos pelos processos de colonialidade interna, mas que não obstante vinham persistindo no plano da virtualidade (também no sentido deleuziano). Esses agenciamentos são pensados nos termos guattarianos da heterogênese, ou seja, como conexões criativas entre "heterogêneos enquanto heterogêneos", "diferenças enquanto diferenças" (Goldman, 2015). A proposta de Goldman é, nos termos avançados aqui, um esforço importante no sentido de pensar relações de colonialidade interna no Brasil a partir do lado subalterno da diferença colonial. Resta saber em que medida ela permitirá de fato romper com o âmago da gramática hegemônica, uma vez que, ao menos por enquanto, boa parte dos exemplos etnográficos trazidos tende a se referir a domínios privilegiados por ela: as artes, a religião, a cultura.

Já a perspectiva da antimestiçagem de José Antonio Kelly Luciani (2016) busca não extrair o polo hegemônico (no caso, seu foco é a ideologia nacional da mestizaje na Venezuela), mas contrapôlo a concepções indígenas sobre mistura (em especial, mas não exclusivamente, ianomâmi). Com base no historiador venezuelano Carrera Damas, Luciani discute a posição ambivalente do “dominador cativo" criollo (do qual Freyre seria um exemplo no caso brasileiro), dividido entre a relação de identidade-diferença para com o antigo 
império espanhol por um lado, e para com os grupos indígenas domésticos por outro. De modo interessante, Luciani aponta para as instabilidades e contradições no plano do próprio polo hegemônico, conformando assim uma visão complexa da colonialidade interna na América Latina que se aproxima daquela que busquei esboçar aqui.

A tese da antimestiçagem contém, ainda, uma crítica da cultura que também ecoa algumas das considerações feitas acima. O mecanismo analítico de Luciani (2016, p. 87) se concentra na "equivocação" entre o "fazer sociedade" da "máquina de miscigenação" das elites criollas, que tem buscado operar historicamente os mecanismos de integração e uniformização típicos dos processos de construção do estado-nação (ou da produção de hegemonia), e o "fazer pessoas" da "máquina antimestiçagem" indígena, movida por um tipo clastreano de política bem diferente daquele que subjaz as disputas por hegemonia nas sociedades "com história" e "com estado". Nesse sentido, ele pondera,

[...] não é nenhuma coincidência, por exemplo, que o Estado tenha acalentado a 'cultura' como uma avenida relacional direcionada aos povos indígenas, de uma forma que não encontra nenhum paralelo com 'sociedade', apesar $\mathrm{da}$ - ou precisamente devido a - sua centralidade para o Estado. (Luciani, 106, p. 14)

Em termos mais próximos aos que coloquei aqui, ele sugere que “[...] quando se trata dos povos indígenas, qualquer sinal de autonomia ou de reconhecimento por parte da elite criolla sempre tem se limitado ao plano da cultura" (Luciani, 2016, p. 22).

Com efeito, tanto na antropologia como no campo pós-colonial tem-se falado sobre possíveis "armadilhas" implicadas em processos de reinvindicação de direitos nos termos colocados pela gramática do multiculturalismo (Hanchard, 2001; Povinelli, 2002; Coelho de Souza, 2010). Não obstante o resgate do seu caráter político - e, em sua origem, anti-hegemônico (Elias, 1994) - como base para direitos diferenciados por parte do estado, a gramática da cultura insiste em se compor nos termos de divisores clássicos como natureza-cultura, cultura-sociedade, cultura-materialidade, alta-baixa cultura (Williams, 2007). No Brasil, além de Luciani, Marcela Stockler Coelho de Souza (2010) avançou uma importante crítica neste sentido, ao discutir o 
trabalho realizado pela gramática da cultura no contexto de normas emergentes de proteção ao patrimônio imaterial. Ela é especialmente atenta ao modo como o "[...] acoplamento da Cultura das elites ao material, ou tangível, e das culturas do(s) povo(s) ao imaterial, ou intangível" (Coelho de Souza, 2010, p. 149) implícito no aparato de patrimonialização objetifica, de forma problemática pois potencialmente colonizadora (termo meu), formas de vida indígenas que operariam por meio de uma dinâmica profundamente diferente entre o material e o imaterial, o visível e o invisível.

Essas e outras discussões indicam que, embora a reificação da cultura possa trazer, por um lado, ganhos de direitos, sem alicerces fortes na "sociedade" ela pode acabar sendo mais uma engrenagem da máquina de colonialidade. No contexto do projeto de patrimonialização dos sistemas agrícolas do Alto Rio Negro, Carneiro da Cunha (2012) intuiu tal perigo ao defender o reconhecimento da agrobiodiversidade indígena como sistema total. Seria preciso, neste sentido, manter a separação entre o sistema indígena e o seu entorno (a sociedade nacional), pois se trata aqui não apenas de cultura, mas de todo um modo de vida que implica, inclusive, a garantia de um território. Coelho de Souza faz ressalva semelhante com relação à "diferença entre nossas descrições da vida alheia em termos de um tal conceito [cultura] e as autodescrições alheias [dos nativos], que podem muito bem prescindir inteiramente dele" - diferença esta que as "políticas culturais informadas por este conceito se arriscam a apagar" (Coelho de Souza, 2010, p. 152) .

Finaliza-se sugerindo que o mesmo poderia ser dito a respeito da noção antropológica de cultura. Embora pretenda falar da cultura, se não como "coisa", ao menos como processos que existem no mundo, out there, a antropologia - como qualquer outra prática de conhecimento - o faz a partir de uma escala circunscrita, ancorada na academia. Assim como o fator de liberação brilhantemente analisado na etnografia original de Latour não existe fora do laboratório sem uma rede sociotécnica equivalente (Latour; Woolgar, 1997), também a noção antropológica de cultura (que internamente, são várias) é colocada em risco ao deixar a esfera acadêmica e suas interfaces imediatas para circular em outras 
escalas. Como nos casos de transferência de tecnologias (Cesarino, 2017b), a cultura como "objeto de fronteira" (Star; Griesemer, 1989) só é capaz de se difundir pela sociedade ao se mostrar flexível o suficiente para se transformar de acordo com matrizes relacionais e condições de eficácia próprias de outras escalas, porém a ponto de, às vezes, nós não a reconhecermos mais como tal - e, por consequência, deixarmos de nos responsabilizar por ela e pelos jogos de colonialidade nos quais ela passa a operar. Assim, ao mesmo tempo em que a antropologia pode ganhar acrescentando ao seu olhar o tipo de atenção reflexiva mais própria do campo pós-colonial, com sua ênfase na história e nas relações de poder, é interessante que os dois campos não se confundam, se mantendo como fontes diferentes de complexidade criativa para pensar processos que são, eles mesmos, complexos e criativos.

\section{Notas}

1 Agradeço aos participantes do colóquio "Alternativas etnográficas à mestiçagem" realizado no PPGAS/UFSC em novembro de 2016, bem como aos participantes do GT "Antropologia e crítica pós-colonial", na Reunião Brasileira de Antropologia de 2016, pelas conversas que deram origem a muitos dos pontos elaborados neste artigo.

2 Na antropologia internacional, em especial estadunidense, também houve um importante "momento gramsciano" nos anos de 1990 (Crehan, 2002), que parece não ter ecoado de forma significativa no Brasil.

3 Parece interessante, ainda, compor a noção de colonialidade com a de "diferença colonial" (Mignolo, 2005b). O que me interessa nesta noção é o fato de ela indicar não uma exterioridade ontológica preexistente ao encontro colonial, mas uma relação entre colonizador e colonizado onde o primeiro produz o último, e a si mesmo, ao inscrever uma diferença. Essa relação não é fixa nem unidimensional, mas segue o complexo fluxo da história, e é a partir do espaço aberto por ela que os subalternos lançam desafios à epistemologia hegemônica, sempre a partir de sua práxis política.

4 "Vivendo quatrocentos anos no litoral vastíssimo, em que pelejam reflexos da vida civilizada, tivemos de improviso, como herança inesperada, a República. Ascendemos, de chofre, arrebatados na caudal dos ideais modernos, deixando na penumbra secular em que jazem, no âmago do país, um terço de nossa gente. Iludidos por uma civilização de empréstimo; respingando, em faina cega de copistas, tudo o que de melhor existe nos códigos orgânicos de outras nações, tornamos, revolucionariamente, fugindo ao transigir mais ligeiro com as exigências da nossa própria nacionalidade, mais fundo o contraste entre o nosso modo de viver e o daqueles rudes patrícios mais estrangeiros nesta terra do que os imigrantes da Europa." (EUCLIDES DA CUNHA, 2007, p. 208-9)

5 Trago a conhecida passagem de The Souls of Black Folk: "É um sentimento particular, esta dupla consciência, esta sensação de sempre olhar para o seu eu através dos olhos dos outros, de medir a sua alma com a régua de um mundo que o observa 
com divertido desprezo e piedade. Sua dualidade é constantemente sentida - um americano, um negro; duas almas, dois pensamentos, dois esforços inconciliáveis; dois ideais em guerra em um só corpo escuro, cuja força tenaz apenas é o que o impede de se dilacerar" (Du Bois, 1999, p. 9).

6 Na realidade, bem antes - pensemos como o elemento do "meio" (desta vez, enquanto ambiente) é central, por exemplo, em um livro como Os Sertões.

7 Basta lembrar as tensões entre modernismo e regionalismo na própria obra de Freyre, e entre esta e outras, como as dos modernistas paulistas. Tanto em Freyre como nos modernistas, assim como em outros (Roberto DaMatta, para citar um exemplo próximo), interpretações da cultura ou identidade brasileiras sempre implicam algum movimento de scaling up, seja a partir do nordeste, de São Paulo, do Rio de Janeiro...

\section{Referências}

ANDERSON, Benedict. Comunidades Imaginadas: reflexões sobre a origem e a difusão do nacionalismo. São Paulo: Companhia das Letras, 2008.

ASCHCROFT, Bill. Modernity's first-born: Latin America and postcolonial transformation. ARIEL: A Review of International English Literature, [S.l.], v. 29, n. 2, 1998, p. 7-29.

BALANDIER, Georges. A situação colonial: abordagem teórica. Cadernos CERU, [S.l.], v. 25, n. 1, p. 33-58, 2014.

BALLESTRIN, Luciana. América Latina e o giro decolonial. Revista Brasileira de Ciência Política, [S.l.], n. 11, p. 89-117, 2013.

CALDEIRA, Teresa. Cidade dos Muros: crime, segregação e cidadania em São Paulo. São Paulo: Editora 34; EDUSP, 2000.

CAÑIZARES-ESGUERRA, Jorge. Nature, Empire and Nation: explorations in the history of Science in the Iberian world. Stanford: Stanford University Press, 2006.

CARDOSO DE OLIVEIRA, Roberto. Aculturação e fricção interétnica. América Latina. Revista do Centro Latinoamericano de Ciencias Sociales, [S.l.], v. 6, n. 3, 1963.

CARDOSO DE OLIVEIRA, Roberto. A noção de colonialismo interno na etnologia. Tempo Brasileiro, Rio de Janeiro, v. 4, n. 8, p. 105-112, 1966.

CARDOSO DE OLIVEIRA, Roberto. O movimento dos conceitos na antropologia. In: CARDOSO DE OLIVEIRA, Roberto. O Trabalho do Antropólogo. Brasília: Paralelo 15, 2006. p. 37-52.

CARNEIRO DA CUNHA, Manuela. Questões suscitadas pelo conhecimento tradicional. Revista de Antropologia, São Paulo, v. 55, n. 1, p. 439-464, 2012. 
CARVALHO, José Jorge de. Poder e silenciamento na representação etnográfica. Série Antropologia, Brasília, n. 316, p. 1-21, 2002.

CARVAlHO, José Murilo de. A Formação das Almas: o imaginário da República no Brasil. São Paulo: Companhia das Letras, 1990.

CESARINO, Letícia. Brazilian postcoloniality and South-South cooperation: a view from anthropology. P: Portuguese Cultural Studies, Utrecht, n. 4, p. 85-113, 2012.

CESARINO, Letícia. Anthropology and the South-South encounter: on "culture" in Brazil-Africa relations. American Anthropologist, Arlington, v. 119, n. 2, p. 333-341, 2017a.

CESARINO, Letícia. Communication in international technical cooperation: an anthropological systems approach. In: REYES-GALINDO, Luis; DUARTE, Tiago (Org.). Intercultural Communication and Science and Technology Studies. Cham: Palgrave Macmillan. p. 207231.

CHAKRABARTY, Dipesh. Provincializing Europe: postcolonial thought and historical difference. Princeton: Princeton University Press, 2000.

CLIFFORD, James; MARCUS, George (Org.). A Escrita da Cultura: política e poética da etnografia. Rio de Janeiro: EdUERJ, 2017.

COELHO DE SOUZA, Marcela S. A cultura invisível: conhecimento indígena e patrimônio imaterial. Anuário Antropológico, Brasília, n. I, 2010 .

COMAROFF, Jean; COMAROFF, John. Ethnicity, Inc. Chicago: Chicago University Press, 2009.

CORONIL, Fernando. Magical State: nature, money and modernity in Venezuela. Chicago: University of Chicago Press, 1997.

CREHAN, Kate. Gramsci, Culture and Anthropology. Berkeley: University of California Press, 2002.

CUNHA, Euclides da. Os Sertões. Rio de Janeiro: Record, 2007.

DU BOIS, W. E. B. As Almas da Gente Negra. Rio de Janeiro: Lacerda Editora, 1999.

ELIAS, Norbert. O Processo Civilizador. Rio de Janeiro: Jorge Zahar, 1994.

ESCOBAR, Arturo. Escobar, Arturo. Worlds and knowledges otherwise: the Latin American modernity/coloniality research program. Cultural Studies, [S.l.], v. 2, n. 2-3, p. 179-210, 2007. 
FABIAN, Johannes. O Tempo e o Outro: como a antropologia estabelece seu objeto. Petrópolis: Vozes, 2013.

FANON, Franz. Pele Negra, Máscaras Brancas. Salvador: EDUFBA, 2008.

FERRERAS, Norberto. Bandoleiros, cangaceiros e matreiros: revisão da historiografia sobre o Banditismo Social na América Latina. História, São Paulo, v. 22, n. 2, p. 211-226, 2003.

FREYRE, Gilberto. Casa Grande \& Senzala: formação da família brasileira sob o regime da economia patriarcal. São Paulo: Global, 2005.

FRY, Peter. Feijoada e soul food. Cadernos de Opinião, [S.l.], n. 4, p. 13-23, 1977.

GOLDMAN, Marcio. Quinhentos anos de contato: por uma teoria etnográfica da (contra)mestiçagem. Mana, Rio de Janeiro, v. 21, n. 3, p. 641-659, 2015.

GONZÁLEZ CASANOVA, Pablo. Sociedad plural, colonialismo interno y desarrollo. América Latina - Revista do Centro Latinoamericano de Ciencias Sociales, [S.l.], v. 6, n. 3, 1963.

GONZÁLEZ CASANOVA, Pablo. Colonialismo interno (uma redefinição). In: BORON, Atilio; AMADEO, Javier; GONZALEZ, Sabrina (Org.).

A Teoria Marxista Hoje: problemas e perspectivas. São Paulo: CLACSO, 2007. p. $431-458$.

GRAMSCI, Antonio. Cadernos do Cárcere. Rio de Janeiro: Civilização Brasileira, 1999-2002. $6 \mathrm{~V}$.

HALL, Stuart. A relevância de Gramsci para o estudo de raça e etnicidade. In: SOVIK, Liv (Org.). Da Diáspora: identidades e mediações culturais. Belo Horizonte: Editora UFMG, 2003. p. 294-333.

HANCHARD, Michael. Orfeu e Poder: movimento negro no Rio e São Paulo. Rio de Janeiro: EdUERJ, 2001.

HECHTER, Michael. Internal Colonialism: the Celtic fringe in British national development. Berkeley: University of California Press, 1975.

HIND, Robert. The internal colonial concept. Comparative Studies in Society and History, [S.l.], v. 26, n. 3,p. 543-568, 1984.

HOBSBAWM, E.; RANGER, T. (Org.). A Invenção das Tradições. Rio de Janeiro: Paz e Terra, 1984.

KUHN, Thomas. A Estrutura das Revoluções Científicas. São Paulo: Perspectiva, 1997. 
KUPER, Adam. Cultura, a Visão dos Antropólogos. Bauru: EDUSC, 2002.

LUCIANI, José Antonio K. Sobre a Antimestiçagem. Desterro [Florianópolis]: Cultura e Barbárie, 2016.

QUIJANO, Anibal. Colonialidad y modernidad/racionalidade. Perú

Indígena, Lima, v. 13, n. 29, 1992.

QUIJANO, Aníbal. Colonialidade do poder, Eurocentrismo e América Latina. In: LANDER, Edgardo (Org.). A Colonialidade do Saber: eurocentrismo e ciências sociais. Perspectivas latino-americanas. Buenos Aires: CLACSO, 2005.

QUIJANO, Anibal; WALLERSTEIN, Immanuel. Americanity as a concept, or, the Americas in the modern world-system. International Social Science Journal, [S.l.], v. 44, n. 4, p. 549-557, 1992.

LANDER, Edgardo (Org.). A Colonialidade do Saber: eurocentrismo e ciências sociais: perspectivas latino-americanas. Buenos Aires: CLACSO, 2005.

LATOUR, Bruno; WOOLGAR, Steve. A Vida de Laboratório: a produção dos fatos científicos. Rio de Janeiro: Relume-Dumará, 1997.

LUGONES, María. Rumo a um feminismo descolonial. Revista Estudos Feministas, [S.l.], v. 22, n. 3, p. 935-952, 2014.

MAHMOOD, Saba. Politics of Piety: Islamic revival and the feminist subject. Princeton: Princeton University Press, 2004.

MARQUARD, Leo. South Africa's Colonial Policy. Jonesburg: Institute of Race Relations, 1957.

MASSIP, Nathalie. 2012. The Role of the West in the Construction of American Identity: From Frontier to Crossroads. Caliban, [S.l.], n. 31, p. 239-248, 2012.

MIGNOLO, Walter. Colonial and postcolonial discourse: cultural critique or academic colonialism? Latin America Research Review, [S.l.], v. 28, n. 3, p. 120-134, 1993.

MIGNOLO, Walter. A colonialidade de cabo a rabo: o hemisfério ocidental no horizonte conceitual da modernidade. In: LANDER, Edgardo (Org.).

A Colonialidade do Saber: eurocentrismo e ciências sociais perspectivas latino-americanas. Buenos Aires: CLACSO, 2005a. p. 35-54.

MIGNOLO, Walter. The Idea of Latin America. Malden: Blackwell, 2005b.

MIGNOLO, Walter. The Darker Side of Modernity: global futures, decolonial options. Durham: Duke University Press, 2011. 
MONTERO, Paula; ARRUTI, José M.; POMPA, Cristina. Para uma antropologia do político. In: LAVALLE, A. G. (Org.). O Horizonte da Política: Questões Emergentes e Agenda de Pesquisa, São Paulo, unesp, p. 145-184.

MORAÑA, Mabel; JÁUREGUI, Carlos (Org.). Revisiting the Colonial Question in Latin America. Madrid: Iberoamericana, 2008.

MORAÑA, Mabel et al. (Org.). Coloniality at Large: Latin America and the post-colonial debate. Durham: Duke University Press, 2008.

MUDIMBE, Valentin Yves. A Invenção de África: gnose, filosofia e a ordem do conhecimento. Mangualde (Portugal); Luanda: Edições Pedago; Edições Mulemba, 2013.

PALLARES-BURKE, Maria Lúcia. Gilberto Freyre: um vitoriano nos trópicos. São Paulo: UNESP, 2005.

PEIRANO, Mariza. Antropologia no Plural: três experiências contemporâneas. Brasília: Unb, 1991.

PEIRANO, Mariza. Antropologia brasileira (alteridade contextualizada). In: MICELI, Sérgio (Org.). O que Ler na Ciência Social Brasileira (19701995): Antropologia. São Paulo: Sumaré, 1999. v. I. p. 225-266.

POVINELLI, Elizabeth. The Cunning of Recognition: indigenous alterities and the making of Australian multiculturalism. Durkham: Duke, 2002.

RAMOS, Alcida. Indigenism: ethnic politics in Brazil. Madison: University of Wisconsin, 1998.

REIS, Letícia. "Aquarela do Brasil": reflexões preliminares sobre a construção nacional do samba e da capoeira. Cadernos de Campo, Curitiba, n. 3, p. 5-19, 1993.

RIBEIRO, Gustavo; ESCOBAR, Arturo (Org.). World Anthropologies: disciplinary transformations within systems of power. Oxford; Nova York: Berg, 2006.

SAID, Edward. Orientalismo: o oriente como invenção do ocidente. São Paulo: Companhia de Bolso, 2007.

SANTOS, Boaventura de Sousa. Entre Prospero e Caliban: colonialismo, pós-colonialismo e inter-identidade. Novos Estudos CEBRAP, São Paulo, n. 66, p. 23-52, 2003.

SAHLINS, Marshall. Esperando Foucault, Ainda. São Paulo: CosacNaify, 2016. 
SCHWARCZ, Lília. O Espetáculo das Raças: cientistas, instituições e questão racial no Brasil. São Paulo: Cia. das Letras, 1993.

SCHWARCZ, Lília. Questão racial e etnicidade. In: MICELI, Sérgio (Org.).

O que Ler na Ciência Social Brasileira (1970-1995): Antropologia. São Paulo: Sumaré, 1999. v. I, p. 267-325.

SEGATO, Rita. Los cauces profundos de la raza latinoamericana: una relectura del mestizaje. Crítica y Emancipación, [S.l.], n. 1, p. 11-44, 2010.

SINGH, Amirtjit; SCHMIDT, Peter. Postcolonial Theory and the United States: race, ethnicity, and literature. Jackson: University of Mississippi Press, 2000.

SOUZA LIMA, Antonio Carlos. Um Grande Cerco de Paz: poder tutelar, indianidade e formação do Estado no Brasil. Petrópolis: Vozes, 1995.

STAR, Susan Leigh; GRIESEMER, James. Institutional ecologies, 'translations' and boundary objects: amateurs and professionals in Berkeley's Museum of Vertebrate Zoology, 1907-39. Social Studies of Science, [S.l.], v. 19, n. 3, p. 387-420, 1989.

STAVENHAGEN, Rodolfo. Clases, colonialismo y aculturación en América Latina. América Latina - Revista do Centro Latinoamericano de Ciencias Sociales, México, v. 6, n. 4, 1963.

STOCKING JR., George. Afterword: a view from the center. Ethnos, [S.l.], V. 47, n. 1-2, p. 172-186, 1982.

VELHO, Otávio. Frente de Expansão e Estrutura Agrária. Rio de Janeiro: Zahar, 1972.

VELHO, Otávio. A antropologia e o Brasil, hoje. Revista Brasileira de Ciências Sociais, [S.l.], v. 23, n. 66, 2008.

VELHO, Otávio. O que nos une. Anuário Antropológico, Brasília, n. 2, p. 9-21, 2010.

VIANNA, Hermano. O Mistério do Samba. Rio de Janeiro: Zahar/UFRJ, 1995.

VISWESWARAN, Kamala. Race and the culture of anthropology.

American Anthropologist, Arlington, v. 100, n. 1, p. 70-83, 1998.

VIVEIROS DE CASTRO, Eduardo. Etnologia Brasileira. In: MICELI, Sérgio (Org.). O que Ler na Ciência Social Brasileira (1970-1995):

Antropologia. São Paulo: Sumaré, 1999. v. I. p. 109-223.

VIVEIROS DE CASTRO, Eduardo. Metafísicas Canibais. São Paulo: Cosac \& Naify, 2015. 
WILLIAMS, Raymond. Cultura. Palavras Chave: um vocabulário de cultura e sociedade. São Paulo: Boitempo, 2007.

WILLIAMS, Stephen W. Internal colonialism, core-periphery contrasts and devolution: an integrative comment. Area, [S.l.], v. 9, n. 4, p. 272-278, 1977.

Recebido em 04/08/2017

Aceito em 04/10/2017 